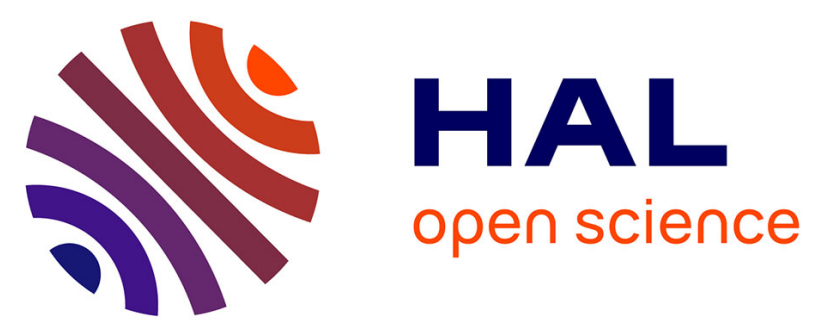

\title{
Oxide or carbide nanoparticles synthesized by laser ablation of a bulk Hf target in liquids and their structural, optical, and dielectric properties
}

Nikolaos Semaltianos, Jean-Michel Friedt, R. Chassagnon, Virginie Moutarlier, Virginie Blondeau-Patissier, Guillaume Combe, Mohamed Assoul, Guy Monteil

\section{To cite this version:}

Nikolaos Semaltianos, Jean-Michel Friedt, R. Chassagnon, Virginie Moutarlier, Virginie BlondeauPatissier, et al.. Oxide or carbide nanoparticles synthesized by laser ablation of a bulk Hf target in liquids and their structural, optical, and dielectric properties. Journal of Applied Physics, 2016, 119 (20), 204903 (10 p.). 10.1063/1.4951740 . hal-01446391

\section{HAL Id: hal-01446391 https://hal.science/hal-01446391}

Submitted on 25 Jan 2017

HAL is a multi-disciplinary open access archive for the deposit and dissemination of scientific research documents, whether they are published or not. The documents may come from teaching and research institutions in France or abroad, or from public or private research centers.
L'archive ouverte pluridisciplinaire $\mathbf{H A L}$, est destinée au dépôt et à la diffusion de documents scientifiques de niveau recherche, publiés ou non, émanant des établissements d'enseignement et de recherche français ou étrangers, des laboratoires publics ou privés. 


\section{OXIDE OR CARBIDE NANOPARTICLES SYNTHESIZED BY LASER}

This manuscript was accepted by J. Appl. Phys. Click here to see the version of record. ABLATION OF A BULK Hf TARGET IN LIQUIDS AND THEIR

\section{STRUCTURAL, OPTICAL AND DIELECTRIC PROPERTIES}

N. G. Semaltianos*a ${ }^{\mathrm{a}}$, J. -M. Friedt ${ }^{\mathrm{b}}$, R. Chassagnon ${ }^{\mathrm{e}}$, V. Moutarlier ${ }^{\mathrm{d}}$, V. Blondeau-

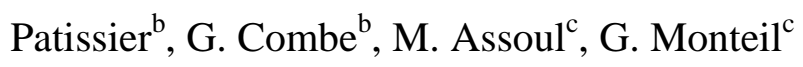

${ }^{a}$ Aristotle University of Thessaloniki, Dept. of Physics, Thessaloniki, 54124, GREECE

bUniversité de Franche-Comté, Femto-st, Dépt. Temps-Fréquence, UMR CNRS 6174, Besançon, 25030, FRANCE

${ }^{c}$ Université de Franche-Comté, Femto-st, Dépt. Mécanique Appliquée, UMR CNRS 6174, Besançon, 25030, FRANCE

dUniversité de Franche-Comté, UTINAM, UMR CNRS 6213, Besançon, 25030, FRANCE

${ }^{\mathrm{e}}$ Université de Bourgogne Franche-Comté, Laboratoire Interdisciplinaire Carnot De Bourgogne, ICB UMR CNRS 6303, Dijon, 21078, FRANCE

\section{Abstract}

Laser ablation of a bulk Hf target in deionized (DI) water, ethanol or toluene was carried out for the production of nanoparticles colloidal solutions. Due to the interaction of the ablation plasma plume species with the species/which are produced by the liquid decomposition at the plumeliquid interface, hafnia $\left(\mathrm{HfO}_{2}\right)$ nanoparticles are synthesized in DI water, hafnium carbide (HfC) nanoparticles in toluene and a mixture of those in ethanol. The hafnia nanoparticles are in the monoclinic low temperature phase and in the tetragonal and fcc high temperature phases. Their size distribution follows log-normal function with a median diameter in the range of 4.3-5.3 nm. Nanoparticles synthesized in DI water have band gaps of 5.6 and $5.4 \mathrm{eV}$, in ethanol 5.72 and $5.65 \mathrm{eV}$ (using low and high pulse energy) and in toluene $3 \mathrm{eV}$. Values for the relative permittivity in the range of 7.74-8.90 were measured for hafnia nanoparticles thin films 


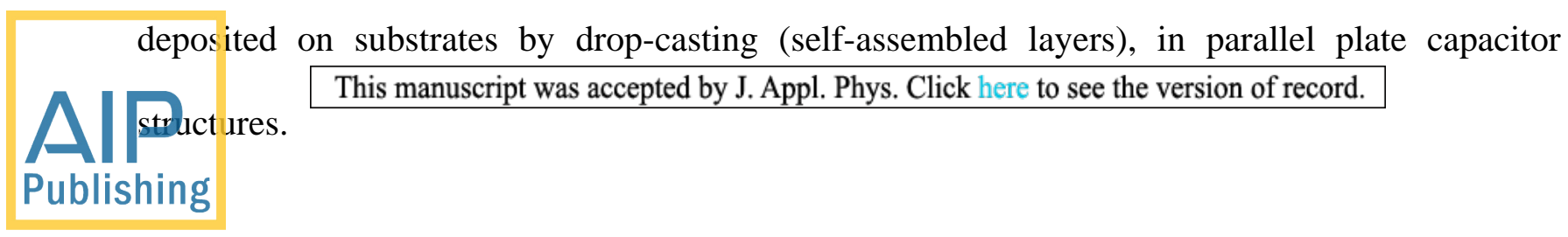

Keywords: laser ablation; nanoparticles; hafnia; hafnium carbide

PACS: 78.67.Bf - Nanocrystals and nanoparticles; 79.20.Eb - Laser ablation; 81.05.Je Ceramics and refractories; 77.22.Ch - Permittivity (dielectric function)

*Corresponding author, E-mail: semal@auth.gr 


\section{Int roduction.}

1. Hf is a tetravalent transition metal element, in the same column in the periodic table as $\mathrm{Zr}$ Publishing a find wide applications in the field of microelectronics as good replacements of silica in field effect transistor gates due to their good balanced combination of properties such as a high dielectric constant, relatively large band gap, large heat of formation, good thermal and chemical stability on $\mathrm{Si}$, large barrier heights at interfaces with $\mathrm{Si}$ and adequate compatibility with $\mathrm{n}^{+}$polysilicon gate electrodes [1]. Hafnia is used as a high refractive index material and in the form of thin films as heat resistant and strongly reflective protective optical coating [2]. Hafnia nanoparticles find applications as luminescent nanomaterials [3], in the medical field for nanoscale radiotherapy of tumor cells by achieving localized intracellular high energy gamma/x-ray radiation dose deposit (due to their high-Z number) [4], in the fabrication of nanocomposites with polymers to be used as $\gamma$-ray scintillators [5], as fillers in proton conducting membranes for proton-exchange membrane fuel cells, in high etch resistance lithographic photoresists for EUV patterning [6] and others.

The most common traditional methods of synthesis of hafnia nanoparticles in solution, involve the reaction of hafnium(IV) ethoxide with benzyl alcohol [7], the reaction of hafnium tetrachloride $\left(\mathrm{HfCl}_{4}\right)$ with potassium hydroxide $(\mathrm{KOH})$ and 3,4-dihydroxy hydrocinnamic acid (DHCA) [8] or just with sodium hydroxide $(\mathrm{NaOH})$ [9], the reaction of hafnium(IV) isopropoxide with $\mathrm{HfCl}_{4}$ and trioctylphosphine oxide (TOPO) as the strongly coordinating solvent $[10]$ or the reaction of hafnium(IV) tert-butoxide with ammonia $\left(\mathrm{NH}_{4} \mathrm{OH}\right)$ in the presence of surfactant [11]. These methods require long reaction times and high temperatures $[7,8,10]$, annealing at usually high temperatures under controlled gas atmospheres of the as synthesized originally amorphous nanoparticles in order to crystallize them $[9,11]$ or vigorous 
washing procedures in order to remove from the nanoparticles' surfaces the coordinating

This manuscript was accepted by J. Appl. Phys. Click here to see the version of record.

ligancs (such as for instance TOPO) which are used during their synthesis [10].

Publishing

hafnium carbide (HfC). This is the most refractory binary compound known with a melting point over $3890{ }^{\circ} \mathrm{C}$, high phase stability and good thermomechanical and thermochemical properties. It has attracted investigations in recent years for ultra-high temperature applications such as in cutting tools, rocket nozzles, space/air craft and thermal-field emitters [12]. It is usually synthesized by the reaction of powder mixtures of some source of carbon such as phenolic resin, citric acid monohydrate, graphite powder and others, with some source of Hf such as pure $\mathrm{Hf}$ metal, $\mathrm{Hf}$ hydride $\left(\mathrm{HfH}_{2}\right)$, hafnia or $\mathrm{HfCl}_{4}$ [11-15]

An alternative method for the synthesis of nanoparticles in solution involves laser ablation of a bulk target material while the material is immersed in a liquid [16-18]. The nanoparticles are formed by the debris which is generated as a result of the material's ablation and a nanoparticles colloidal solution is formed. In case of ablation in water, ultrapure nanoparticle colloidal solutions are produced, without any reaction by-products since the process of nanoparticles synthesis does not involve the use of any chemical precursors and most importantly nanoparticles with bare, ligand-free surfaces are synthesized. This is the main reason why this method has gained popularity and especially in the fabrication of polymernanoparticles nanocomposites since the interaction of the nanoparticles with their environment mainly depends on the properties of the nanopaticles' surface. The produced colloidal solutions are stable against nanoparticles' agglomeration without the need of adding into the solution any stabilizing surfactants, due to the electrostatic repulsion between the nanoparticles because of the surface electrical charge which is generated onto them from their surface partial oxidation and subsequent ionic equilibrium with the liquid $[19,20]$. In addition, the ablation plasma plume experiences an additional compression by the liquid which may result in the formation 
of nanoparticles which are characterized by metastable material phases, difficult or impossible

A to be produced by other methods. Throughout the years, nanoparticles out of a number of Publishiff.

Laser ablation (120 fs, $800 \mathrm{~nm}, 1 \mathrm{kHz}, 0.1-0.36 \mathrm{~mJ})$ of a $\mathrm{Zr}$ target in ammonia or water lead to the formation of zirconia $\left(\mathrm{ZrO}_{2}\right)$ nanoparticles in the cubic or tetragonal/monoclinic phase, respectively [21]. $\mathrm{H}^{+}$and $\mathrm{Al}^{2+}$ - codoped $\mathrm{Al}_{2} \mathrm{O}_{3}$ nanoparticles (rather than aluminium hydrates) with spinel related structures of mainly $\gamma$ - and its monoclinic derivative $\theta$-phase having significant internal compressive stress and defects which exhibit band gap (5.2 eV) much lower than the band gap of $\alpha-\mathrm{Al}_{2} \mathrm{O}_{3}(8.8 \mathrm{eV})$ were synthesized by laser ablation (16 ns, $1064 \mathrm{~nm}, 10$ $\mathrm{Hz}, 850 \mathrm{~mJ})$ of an $\mathrm{Al}$ target in DI water [22] while ablation in aqueous solution of $\mathrm{NaOH}(0.05-1$ M) lead to the fabrication of epitaxial $\beta-\mathrm{NaAlO}_{2}$ and $\gamma-\mathrm{Al}_{2} \mathrm{O}_{3}$ nanoparticles [23]. Hollow amorphous $\mathrm{Al}_{2} \mathrm{O}_{3}$ micro/nanoparticles which may had weak crystallization were synthesized by pulsed $\mathrm{KrF}$ excimer laser ablation $\left(30 \mathrm{~ns}, 248 \mathrm{~nm}, 10 \mathrm{~Hz}, 2.3 \mathrm{~J} / \mathrm{cm}^{2}\right.$ ) of a bulk Al target in distilled water [24]. Laser ablation (90 fs, $800 \mathrm{~nm}, 1 \mathrm{kHz}, 110 \mu \mathrm{J}$ ) of a Cr target in DI water lead to the formation of a mixture of $\mathrm{Cr}_{3} \mathrm{O}_{4}, \mathrm{Cr}_{2} \mathrm{O}_{3}$ and $\mathrm{CrO}_{3}$ nanoparticles, in ethanol to a mixture of $\mathrm{Cr}_{3} \mathrm{O}_{4}, \mathrm{Cr}_{7} \mathrm{C}_{3}$ and of the metastable phase $\mathrm{Cr}_{3} \mathrm{C}_{2-\mathrm{x}}$ nanoparticles while in acetone or toluene to nanoparticles which were in the metastable phase $\mathrm{Cr}_{3} \mathrm{C}_{2-\mathrm{x}}$ [25]. $\mathrm{W}_{2} \mathrm{C}-\mathrm{C}$ core-shell nanoparticles or pearl-like SiC nanorings were synthesized by laser ablation (10 ns, $1064 \mathrm{~nm}, 20 \mathrm{~Hz}, 100 \mathrm{~mJ})$ of a W or Si target, respectively in ethanol [26]. Laser ablation (Nd:YAG laser, $1064 \mathrm{~nm}, 10 \mathrm{~Hz}$, $90 \mathrm{~mJ}$ ) of a Ta target in ethanol lead to the synthesis of $\mathrm{Ta}_{\mathrm{x}} \mathrm{O}$ crystal core/ $\mathrm{Ta}_{2} \mathrm{O}_{5}$ amorphous shell nanoparticles [27].

This paper involves the synthesis of nanoparticles in solution by laser ablation for the first time of a bulk Hf target in DI water, ethanol or toluene. The morphological, structural, optical and dielectric properties of the nanoparticles were measured and compared with the corresponding properties of a similar type of nanoparticles synthesized in the literature by other 
methods. The synthesized nanoparticles exhibit different crystal phases and the underlying

This manuscript was accepted by J. Appl. Phys. Click here to see the version of record.

1 physics for the formation of the different phases in relation to the temperature and pressure Publishing fitions of the plasma plume during its adiabatic expansion in the liquid environment, is discussed. In addition to the band gap absorption, sub-band optical transitions are also observed in the UV-vis absorption spectra and their presence is explained based on the possible formation of defects in the nanoparticles or of any deviations from the perfect stoichiometry. Finally, a general methodology is outlined for the measurement of the dielectric properties of nanoparticles-based thin films.

\section{Experimental Details.}

Laser ablation for nanoparticles generation was carried out in this work using a Q-switched Nd:YAG pulsed laser (pulse width=20 ns) at beam wavelength of $1064 \mathrm{~nm}$ and pulse repetition rate of $1 \mathrm{kHz}$ using pulse energy of 380 or $1194 \mu \mathrm{J}$. The target was a bulk piece of Hf metal (purity $99.5 \%$ ) with thickness of $0.75 \mathrm{~mm}$ and dimensions of $10 \times 10 \mathrm{~mm}$. Before each ablation the target surface was mechanically polished using SiC paper in order to remove any surface oxide layers and expose a clean material's surface. The target was used for ablation immediately after polishing and ablation was carried out with the target lying at the bottom of a beaker filled with $5 \mathrm{ml}$ of the liquid. The height of the liquid above the target surface was $\sim 10 \mathrm{~mm}$. The beam was impinging yertically onto the horizontally lying target at the bottom of the beaker, scanning the target surface in a meander fashion $(5 \mathrm{~mm}$ length, pitch $0.02 \mathrm{~mm}$, scanning speed of $1 \mathrm{~mm} / \mathrm{s}$, 400 overscans) and ablation was carried out for $\sim 15$ mins each time resulting to $\sim 1-1.3 \mathrm{mg}$ of nanoparticles in the $5 \mathrm{ml}$ of each liquid. Formation of the nanoparticles resulted in the initial solvents becoming from transparent to white in the case of ablation in DI water and brownish in the case of ablation in ethanol or toluene (Fig. S1 [64]). The nanoparticles colloidal solutions were characterized by UV-vis spectrophotometry. The synthesized nanoparticles, from solution 
droplets dried out onto carbon coated copper grids, were characterized by Transmission Electron

M Mcroscopy (TEM) and from droplets dried out onto clean glass substrates by X-Ray Diffraction Publish.'ng

Infrared (FTIR) transmission measurements were prepared using the $\mathrm{KBr}$ method, by mixing dried nanoparticles with $\mathrm{KBr}$ (in a ratio of $\sim 8: 168 \mathrm{mg}$ ) and preparing a pellet with thickness of $\sim 1 \mathrm{~mm}$. Crystal structures were determined from the XRD patterns using the software of the instrument (DiffracPlus EVA).

Samples for capacitance measurements were prepared by depositing the nanoparticles as a thin film onto $\mathrm{Au} / \mathrm{Cr}$ (100/20 nm thickness) metallized by RF-sputtering, circular glass substrates (thickness $\sim 0.5 \mathrm{~mm}$, diameter $10 \mathrm{~mm}$ ) by drop casting from the colloidal solutions while keeping the substrates in an oven at temperature of $\sim 60^{\circ} \mathrm{C}$. After completion of the deposition, the samples were kept in the oven at the same temperature for a further $\sim 48 \mathrm{hrs,} \mathrm{for} \mathrm{a} \mathrm{final} \mathrm{drying.} \mathrm{In}$ order to avoid any contamination of the samples, the whole process was performed in a clean room environment. This method provides with a self-assembled layer of nanoparticles which has a quite uniform thickness over the whole substrate surface area (variation of $\sim 10 \%$ ) of $13.72 \pm 1.15 \mu \mathrm{m}$ (data for other samples are reported in Table 1 of the Supplementary Material [64]). The thickness was measured by physically scratching the film surface and measure the depth of the scratches by a white light scanning interferometric microscope. Then a Au film (thickness $\sim 100 \mathrm{~nm}$ ) was deposited onto the nanoparticles layer, by RF-sputtering, using a metallic mask with circular holes with diameters of 0.5, 1.0, 1.5, 2.0 and $2.5 \mathrm{~mm}$ (Fig. S3 [64]). The metallic mask was fabricated from an $80 \mu \mathrm{m}$ thick stainless steel foil, by laser cutting. In this way circular plate capacitors with different diameters were fabricated. The admittance versus frequency of the capacitors was measured in the range 0.1-10 $\mathrm{MHz}$ using a vector network analyzer from which the dielectric constant of the nanoparticles film was determined. 


\section{Re sults and Discussion.}

3. Synthesis of nanoparticles and characterization of their morphological, structural and
Publishing
This l properties.

The laser beam with fluence greater than the ablation threshold of the material produces at the place of incidence on the material's surface a plasma plume of ablated species (neutral atoms or ions). This plasma plume in the case of long pulse laser ablation as at the present case, where the deposition of energy in the material is slow, originates from vaporization of the material melt pool, namely the ablation of the material is via melting and vaporization rather than by sublimation (direct solid to vapour transition) as in the case of ultrashort pulse laser ablation [25]. The nanoparticles are formed by nucleation in the vapour phase (of the plume species) but a large percentage of nanoparticles correspond to material which is directly ejected from the material's surface in the form of molten droplets [28].

TEM images of the nanoparticles are shown in Fig. 1 (a)-(d). It is seen that spherical nanoparticles are generated in DI water and-ethanol while in toluene there are also a few nanoparticles which are not perfectly spherical. This is most probably caused by the low temperature conditions of the plasma plume relative to the high temperature which is required for the reaction of $\mathrm{Hf}$ with $\mathrm{C}$ in comparison to the one which is required for its reaction with oxygen species. These conditions result to the reduced mobility of surface atoms during nuclei coalescence and thus to the imperfect smoothing of grain boundaries. These nanoparticles are formed by nuclei whose temperature is not high enough to allow the transport of interface atoms during coalescence [16-18]. The size distribution histograms of the nanoparticles by counting approximately 400 nanoparticles in images of nanoparticles ensembles obtained on different areas on each grid, are shown in Fig. 1 (e)-(h). The histograms are described quite well by lognormal functions with median diameters of $\left\langle\mathrm{d}_{0}\right\rangle=4.6,5.3,4.5$ and $4.3 \mathrm{~nm}$ and standard deviations of $\sigma=0.55,0.56,0.52$ and 0.45 , respectively. 
XRD patterns measured from the nanoparticles are shown in Fig. 2. The as measured This manuscript was accepted by J. Appl. Phys. Click here to see the version of record.

1 paterns are presented without any smoothing of the curves applied for noise reduction. In the Publishing nanoparticles are also plotted for comparison. Analysis of the patterns using the software for the diffractometer reveals that the peaks observed in the patterns for the nanoparticles synthesized in DI water (Fig. 2 (a)) correspond to hafnia in the monoclinic, tetragonal and fcc phase [29]. The monoclinic is an equilibrium phase of hafnia and is observed at normal conditions of pressure and temperature. The tetragonal and fcc are high temperature phases of hafnia and are observed at temperature above $\sim 1700{ }^{\circ} \mathrm{C}$ and $\sim 2500{ }^{\circ} \mathrm{C}$, respectively, also at low pressure [30]. In traditional method of synthesis of hafnia nanoparticles these phases can be stabilized at much lower temperatures but by the addition into hafnia of rare earth dopants such as $\mathrm{Y}, \mathrm{Yb}, \mathrm{Gd}$ and others [31,32] or $\mathrm{Si}[33]$. The origin of the peaks at $36.646^{\circ}, 48.203^{\circ}$ and $55.687^{\circ}$ which are observed in the patterns for the nanoparticles synthesized in DI water (labeled with the symbol \#) is still unknown, but they might be related to the orthorhombic phase of hafnia with space group Pbca termed as OrthoI which was determined from neutron diffraction studies [34]. This is a high pressure phase of hafnia which is observed in the pressure range of 4-14 GPa [30]. Formation of hafnia nanoparticles is due to the interaction (oxidation) of the hafnium plasma plume species with the oxygen species which are produced at the plume-liquid interface by the thermolysis of water because of the extreme temperature of the plume. The presence in the synthesized nanoparticles of the crystal phases with different stabilization conditions of temperature and pressure is explained by the highly non-equilibrium conditions of the plasma plume. At the start of the expansion of the plume when its temperature is high, the fcc phase is formed and then as the plume expands and adiabatically cools, the tetragonal and monoclinic phases are formed. The high pressure which is required for the formation of the orthorhombic phase is provided by the "compression" which the plume experiences by the liquid during its 
adiabatic expansion in the liquid confined environment [16-18]. When later the plume expansion

This manuscript was accepted by J. Appl. Phys. Click here to see the version of record.

1 quenches the high temperature and pressure phases are "frozen" in the generated nanoparticles. Publishing

using higher pulse energy of $1194 \mu \mathrm{J}$ become stronger in intensity as compared to the peaks for the nanoparticles synthesized using lower pulse energy of $380 \mu \mathrm{J}$ (due to the higher quantity of material produced by the ablation), their relative intensities ratio remains approximately the same (Fig. S2 [64]). This indicates that the relative percentage of each crystal phase (monoclinic, tetragonal and fcc) in each nanoparticles ensemble is approximately the same, independent of the pulse energy used at least in the energies range used in this work.

The peaks in the pattern for the nanoparticles synthesized in ethanol (Fig. 2 (b)) correspond to hafnia in the monoclinic, tetragonal and fcc phases and also to HfC $[29,35]$. The peaks in the pattern for the nanoparticles synthesized in toluene (Fig. 2 (c)) correspond to HfC while the peak at $45.494^{\circ}$ to pure $\mathrm{Hf}$ with hexagonal lattice [36]. The oxide nanoparticles in the case of ablation in DI water or ethanol are formed by the interaction of the plasma plume species with the oxygen species which are produced by the liquid decomposition at the plume-liquid interface [25]. The carbide nanoparticles are formed by the interaction of the plume species with the carbon from the pyrolysis of the liquid (carburization of the plume species). The presence of pure Hf nanoparticles in addition to the $\mathrm{HfC}$ ones is due to the incomplete carburization of the plume species due to the insufficient amount of carbon atoms relative to the amount of Hf species available for reaction as well as to the relatively high temperature which is required for the reaction of the metal with carbon as compared to the one which is required for its reaction with oxygen, as mentioned previously. These are mainly the larger nanoparticles which are ejected directly from the target material as melted droplets.

UV-vis absorption spectra from the nanoparticles colloidal solutions are shown in Fig. 3. Considering a direct band gap, parabolic valence and conduction bands and negligible 
reflectance at low wavelengths, the band gap of the nanoparticles can be found from the plot of

A $(\alpha \omega)^{2}$ versus energy ( $\left.\hbar \omega\right)$ by the interception of the extrapolation of the linear part of the curve Publishing. (high energies) with the horizontal (energy) axis $(\hbar \omega=0)$ (Fig. 4). Small deviation from the linearity might be caused by the fact that tetragonal hafnia has an indirect band gap [37]. Band gap values of 5.6 and $5.4 \mathrm{eV}$, are obtained for the nanoparticles synthesized in DI water using low and high pulse energy, respectively (Fig. 4(a)). A large variation of the band gap values of hafnia nanoparticles or thin films exists in the literature. A value of $5.55 \mathrm{eV}$ was measured for pure hafnia [38]. A value of $6.02 \mathrm{eV}$ was reported for the band gap of hafnia nanoparticles in the monoclinic phase with an average diameter of $\sim 15.5 \pm 2 \mathrm{~nm}$ [9]. A band gap value of 5.65 $\mathrm{eV}$ was reported for $500 \mathrm{~nm}$ thick hafnia thin films in the monoclinic phase [39]. Band gap values in the range of 5.85-5.90 eV were reported for monoclinic hafnia thin films with thicknesses between 5 and $40 \mathrm{~nm}$ while lower values in the range of 5.61-5.80 eV were reported for mixed monoclinic, orthorhombic and tetragonal phase films [40]. In mixed monoclinic and cubic phase yttria-doped hafnia thin films the band gap was observed to increase with the percentage of the cubic phase as the film thickness was increasing, from 5.60 $( \pm 0.03) \mathrm{eV}$ for pure monoclinic phase films to $5.70-5.85( \pm 0.04 \mathrm{eV})$ for mixed films to 6.05 $( \pm 0.03) \mathrm{eV}$ for pure cubic phase films [41]. Band gaps in the region of 5.50-5.85 eV were obtained for hafnia thin films which were thermally annealed in the $500-1000{ }^{\circ} \mathrm{C}$ temperature range, assuming indirect transitions [42]. The higher value for the band gap which is obtained for the nanoparticles synthesized using a lower energy as compared to the value for the band gap for the nanoparticles synthesized using a higher energy might be due to the quantum confinement effect because of the smaller median diameter of the nanoparticles (4.6 as compared to $5.3 \mathrm{~nm}$, Fig. 1(e) and (f)), similarly to the case of hafnia thin films $(2,3$ or $4 \mathrm{~nm}$ thickness) to which the increase of the band gap was attributed to the quantum confinement effect along the vertical direction [43] in analogy with quantum well heterostructures. 
For the nanoparticles synthesized in ethanol a band gap value of $5.65 \mathrm{eV}$ is determined

This manuscript was accepted by J. Appl. Phys. Click here to see the version of record.

1 and $5.72 \mathrm{eV}$ for the nanoparticles synthesized using lower energy) (Fig. 4 (b)). However it is Publishing seep $_{\text {that }}$ there are also weak bands in the absorption spectra (Fig. 3 (b)) peaked at around 215 and $240 \mathrm{~nm}$ which result in an energy value of 4.95 and $3.8 \mathrm{eV}$, respectively $(5.1$ and $3.85 \mathrm{eV}$ for the nanoparticles synthesized using low energy) (Fig. 4 (b)). Such bands with energy lower than the band gap of the material have also been observed previously in hafnia thin films $[44,40]$ and were found to originate from defects states produced by the distortion of bonds at the internal boundaries of the nanocrystalline grains which are present in the nanoparticles (grain-boundary defect states) [45] or from possible oxygen vacancies due to a deviation of the elemental stoichiometry of the nanoparticles from that of hafnia's [40]. These states act as bulk traps in advanced Si devices and are deleterious for the device reliability and performance [45]. The distortion of bonds might be expressed as an increase or decrease of bond lengths in different crystal directions. This is observed at the present work in the XRD patterns (Fig. 2) in which the angles at which few of the peaks corresponding to a particular phase of the material appear, are not exactly equal to the values of the angles at which those peaks are expected to appear according to the corresponding reference tables (a deviation of up to $\sim 0.5 \%$ ). The peaks appear at slightly higher or lower angles indicating a shrinking or an expansion of the unit cell, respectively along the corresponding crystal direction.

For the nanoparticles synthesized in toluene a band gap energy of $3 \mathrm{eV}$ is obtained (Fig. 4 (c)) which is close to the band gap energy measured for HfC powders using EELS spectroscopy [46]. A small deviation might be caused from the presence of also Hf in the nanoparticles ensemble (in addition to $\mathrm{HfC}$ ).

FTIR transmission spectra from hafnia nanoparticles synthesized in DI water are shown in Fig. 5. The bands in the low wavenumbers region at 610, 748 and $642 \mathrm{~cm}^{-1}$ are phonon modes of monoclinic and tetragonal hafnia, respectively [47-49]. The band at $1587 \mathrm{~cm}^{-1}$ is due 
to $\mathrm{Hf}-\mathrm{OH}$ [47] while the band at $3410 \mathrm{~cm}^{-1}$ is a O-H stretching band which corresponds to $\mathrm{OH}$

Aroups either bonded to $\mathrm{H}$ in molecular water or to $\mathrm{Hf}$ (Hf-OH) [50]. This indicates the Publishing ligands on their surfaces. The band at $1630 \mathrm{~cm}^{-1}$ is a $\mathrm{H}-\mathrm{OH}$ bending vibration of molecular water [47] but it may also correspond to Hf-H bonds [51] while the bands at 1022, 1354, 1420, 2854 and $2928 \mathrm{~cm}^{-1}$ originate from $\mathrm{C}-\mathrm{O}$ vibrations in $\mathrm{CO}_{2}$ or $\mathrm{C}-\mathrm{H}$ vibrations in hydrocarbons from the ambient atmosphere [50] as well as all the remaining unmarked peaks in the spectrum.

\subsection{Dielectric properties of hafnia nanoparticles.}

A schematic diagram of the structure of the samples which were fabricated for the investigation of the dielectric properties of hafnia nanoparticles is shown in Fig. 6 [52]. The equivalent circuit is a parallel plates capacitor where the top and bottom plates are the gold thin films and the dielectric between the capacitor plates consists of the nanoparticles self assembled layer.

The measured $\operatorname{Re} Y$ and $\operatorname{Im} Y$ of the admittance versus frequency (Supplementary Material [64]) are shown in Fig. 7 (a) and (b) for the four devices with different surface areas. From the slopes of the curves of $\operatorname{Im} Y$ versus $f$ (Fig. 7 (b)) the capacitance $\left(C^{\prime}\right)$ versus area (A) was determined and is plotted in Fig. 7 (d). From the slope of the line and taking into account the film thickness, the relative permittivity of the nanoparticles film was determined as: $\varepsilon_{r}^{\prime}=7.74 \pm 1.40$. The slopes of the curves of $\operatorname{Re} Y$ versus $f$ determined from Fig. 7 (a) versus the area $(A)$ are plotted in Fig. 7 (c) and from the slope of the line the imaginary part of the relative permittivity was determined as: $\varepsilon_{r}=0.32 \pm 0.07$ Thus the loss tangent was determined as: $\tan \delta=0.042 \pm 0.001$. Values for the relative permittivity and loss tangent for other samples are reported in Table 1 and Fig. S5 and S6 (Supplementary Material) [64]. 
The value for the relative permittivity which is obtained here is by almost three times This manuscript was accepted by J. Appl. Phys. Click here to see the version of record.

A lower than the value reported for bulk hafnia $\left(\varepsilon_{\mathrm{HfO}_{2}}=25\right)$ [1]. A range of different values for Publishing

the relative permittivity of hafnia have been reported in the literature including also relatively

low values. Based on the numerous reports in the literature on the subject, it is concluded that in general the relative permittivity of hafnia thin films depends on the crystal structure of the film but also on the film deposition method (wet chemical or dry physical or chemical methods) [1]. The relative permittivity of uniform and continuous hafnia thin films deposited by atomic layer deposition (ALD) was measured equal to 20 [53]. A value of 16 was reported for mixed monoclinic and tetragonal phase thin films [54]. In studies of the relative permittivity of hafnia nanopowder (pure moniclinic phase) the permittivity of relatively thick layers (1.5-2.5 mm thickness) was measured to take the value of $\sim 10.5$ at $10^{-2} \mathrm{~Hz}$ and $180{ }^{\circ} \mathrm{C}$ [55]. Hafnia thin films deposited by Molecular Beam Epitaxy were measured to have dielectric constant of around 19-20 [56]. A value of 7.5 was measured for amorphous hafnia thin films deposited on Si substrates by pulsed laser deposition (PLD) while upon annealing the films at $500{ }^{\circ} \mathrm{C}$, either in air or nitrogen atmosphere, the structure was transformed to monoclinic or orthorhombic and with higher values of the dielectric constant of 40.8 and 25.1, respectively [57]. The increase of the dielectric constant was attributed to both the densification of the film morphology caused by the heating and to the change of the crystal structure. Higher values for the dielectric constant in the region of 17-24 were measured for as deposited hafnia thin films, deposited by PLD on Si substrates heated at $700{ }^{\circ} \mathrm{C}$ [58]. Calculations have shown that the relative permittivity of hafnia very much depends on its crystal structure with values reported as 26.17 for the cubic phase, 28.54 for the tetragonal phase and 15.47 for the monoclinic phase [59]. Low values of the relative permittivity in the range of 5.6-6.4 were also measured for hafnia thin films of thickness 10 or $30 \mu \mathrm{m}$ almost independent on the film thickness, which were deposited on substrates by PLD (laser intensity $=10^{10} \mathrm{~W} / \mathrm{cm}^{2}$ ) [60]. The crystal structure 
of hafnia was a mixture of monoclinic, tetragonal and cubic [61]. By mechanically

A conpessing the films the permittivity was measured to take higher values in the range of 11.7Publishing. na the the low value of the permittivity for the as deposited films was attributed to the presence of air voids in the gaps between the nanoparticles (the as deposited films had $60 \pm 5 \%$ porosity which was decreasing to $20 \pm 5 \%$ for the compressed films). If we assume that the low value for the permittivity which we obtain here is due to the presence of air-voids in the films (Fig. 6) then using the Effective Medium Approximation (EMA) [62,60] we can estimate the percentage of porosity for the films studied here. According to the EMA the dielectric constant of mixed phase materials is described by the following relation:

$$
f_{a} \frac{\varepsilon_{a}-\varepsilon}{\varepsilon_{a}+2 \varepsilon}+f_{b} \frac{\varepsilon_{b}-\varepsilon}{\varepsilon_{b}+2 \varepsilon}=0
$$

with

$$
f_{a}+f_{b}=1
$$

where $\varepsilon_{a}, \varepsilon_{b}$ and $f_{a}, f_{b}$ are the dielectric constants of the two phases a and $\mathrm{b}$ and their relative percentage composition, respectively, and $\varepsilon$ is the dielectric constant of the effective medium (nanoparticles+air). By taking into account that: $\varepsilon \equiv \varepsilon_{r}^{\prime}=7.74$ and $\varepsilon_{b} \equiv \varepsilon_{\text {air }}=1$, then if we consider $\varepsilon_{a} \equiv \varepsilon_{\mathrm{HfO}_{2}}=25$ equal to the value for bulk hafnia [1], the percentage of voids is estimated equal to $51 \%$. Data for the other samples are given in Table 1 (Supplementary Material) [64]. Although mechanical compression of the nanoparticles thin films leading to an increase of the measured dielectric constant was adopted as a method for confirming the presence of air voids in the film as responsible for the measured low value of the dielectric constant, however compression of the film might have an obvious effect in the shape and size/size distribution of the nanoparticles or even in their crystal structure. For instance, previous studies have shown that the interface strain of hafnia nanoparticles thin film with the 
underlying substrate causes the presence of cubic and tetragonal phases in addition to the

A monoclinic phase [63,1]. Compression of the nanoparticles film might induce a mechanical Publishing in the nanoparticles and also lead to a deformation of the shape of the nanoparticles and/or causing the nanoparticles to effectively join together in the form of a bulk material thus resulting to a change of the crystal structure of the nanoparticles as that was originally formed by the synthesis conditions. Hafnia thin films are typically used in device fabrication and other applications as they are deposited, since compression or any other attempt for a post-deposition modification of the morphology or structure of the film might interfere with the device structure and cause unpredictable errors, and according to the literature the dielectric constant of the film systematically depends not only on the crystal structure of the material but also on the method of deposition. In this work the nanoparticles were deposited on the substrate by drop-casting from the colloidal solution, forming a self-assembled layer and approximately the same value for the dielectric constant within experimental error was measured for a number of samples which were deposited under the same-conditions. This indicates a consistency of the measurements in relation to the set experimental conditions and establishes the value for the dielectric constant which is measured here as the value which is obtained by adopting this particular method for the deposition of the nanoparticles thin films, that of drop-casting.

\section{Conclusions.}

In this work the laser ablation products of a bulk Hf target in liquids were investigated. The interaction of the plasma plume species with the oxygen or carbon species originating from the thermal decomposition of water, ethanol or toluene lead to the direct, one-step synthesis of $\mathrm{HfO}_{2}$ or $\mathrm{HfC}$ nanoparticles. Due to the laser ablation synthesis the nanoparticles have bare, ligand-free surfaces which is advantageous for their use in high k-dielectric structures, in the densification process of ceramics by hot pressing or plasma sintering, in the 


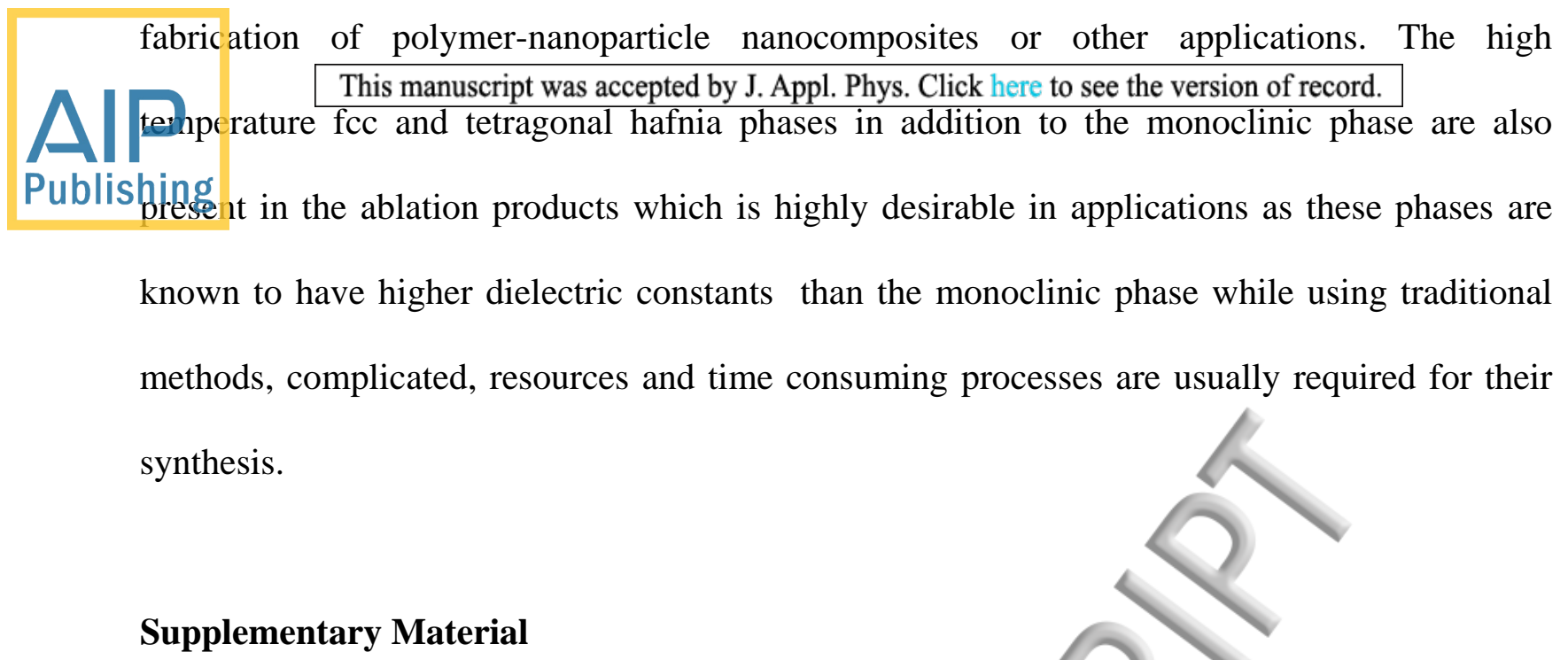

See supplementary material for additional information. 


\section{References}

Alliniting

This manuscript was accepted by J. Appl. Phys. Click here to see the version of record.

Publishing. M. Khoshman, A. Khan and M. E. Kordesch, Surf. Coat. Tech., 202, 2500 (2008).

[3] S. A. Eliziário, L. S. Cavalcante, J. C. Sczancoski, P. S. Pizani, J. A. Varela, J. W. M. Espinosa and E. Longo, Nanoscale Res. Lett., 또, 1371 (2009).

[4] L. Magglorella, G. Barouch, C. Devaux, A. Pottler, E. Deutsch, J. Bourhls, E. Borghl and L. Levy, Future Oncol., $\underline{8}, 1167$ (2012).

[5] C. Liu, T. J. Hajagos, D. Kishpaugh, Y. Jin, W. Hu, Q. Chen and Q. Pei, Adv. Funct. Mater., 25, 4607 (2015).

[6] W. J. Bae, M. Trikeriotis, J. Sha, E. L. Schwartz, R. Rodriguez, P. Zimmerman, E. P. Giannelis and C. K. Ober, J. Mater. Chem., 20, 5186 (2010).

[7] N. Pinna, G. Garnweitner, M. Antonietti and M. Niederberger, Adv. Mater., 16, 2196 (2004).

[8] A. Sahraneshin, S. Asahina, T. Togashi, V. Singh, S. Takami, D. Hojo, T. Arita, K. Minami and T. Adschiri, Cryst. Growth Des., 12, 5219 (2012).

[9] A. Ramadoss, K. Krishnamoorthy and S. J. Kim, Mater. Lett., 75, 215 (2012).

[10] J. Tang, J. Fabbri, R. D. Robinson, Y. Zhu, I. P. Herman, M. L. Steigerwald and L. E. Brus, Chem. Mater.,1ㅌ, 1336 (2004).

[11] G. S. Chaubey, Y. Yao, J. P. A. Makongo, P. Sahoo, D. Misra, P. F. P. Poudeu and J. B. Wiley, RSC Adv., 2, 9207 (2012).

[12] E. J. Wuchina, E. Opila, M. M. Opeka, W. Fahrenholtz and I. G. Talmy, Electrochem. Soc. Interface, 16(4), 30 (2007).

[13] L. E. Toth, "Transition Metal Carbides and Nitrides", Academic Press, New York, 1971.

[14] L. Feng, S. -H. Lee, H. Wang and H. -S. Lee, J. Eur. Ceram. Soc., 35, 4073 (2015). 
[15] B. Matović, B. Babić, D. Bučevac, M. Čebela, V. Maksimović, J. Pantić and M. This manuscript was accepted by J. Appl. Phys. Click here to see the version of record.

Mljković, Ceram. Int., $\underline{39}, 719$ (2013).

Publishipgog(i. W. Yang, Prog. Mater. Sci., 52, 648 (2007).

[17] H. Zeng X. -W. Du, S. C. Singh, S. A. Kulinich, S. Yang, J. He and W. Cai, Adv. Funct. Mater., 22, 1333 (2012).

[18] Z. Yan and D. B. Chrisey, J. Photoch. Photobio. C, 13, 204 (2012).

[19] M. Shoji, K. Miyajima and F. Mafuné, J. Phys. Chem. C, 112, 1929 (2008).

[20] W. Guo and B. Liu, ACS Appl. Mater. Interfaces, 4, 7036 (2012).

[21] D. Tan, G. Lin, Y. Liu, Y. Teng, Y. Zhuang, B. Zhu, Q. Zhao and J. Qiu, J. Nanopart. Res., $\underline{13}, 1183(2011)$.

[22] I. L. Liu, P. Shen and S. Y. Chen, J. Phys. Chem. C, 114, 7751 (2010).

[23] I. L. Liu, B. C. Lin, P. Shen and S. Y. Chen, J. Phys. Chem. C, $\underline{115}, 4994$ (2011).

[24] Z. Yan, R. Bao, Y. Huang and D. B. Chrisey, J. Phys. Chem. C, 114, 11370 (2010).

[25] N. G. Semaltianos, E. Hendry, H. Chang and M. L. Wears, RSC Adv., 4, 50406, (2014).

[26] S. Yang, W. Cai, H. Zhang, H. Zeng and Y. Lei, J. Phys. Chem. C, 115, 7279 (2011).

[27] Q. Li, C. Liang, Z. Tian, J. Zhang, H. Zhang and W. Cai, CrystEngComm, 14, 3236 (2012).

[28] B. N. Chichkoy, C. Momma, S. Nolte, F. von Alvensleben and A. Tünnermann, Appl. Phys. A, $\underline{63}, 109$ (1996).

[29] JCPDS no. 00-006-0318 ( $\mathrm{HfO}_{2}$ (monoclinic)); JCPDS no. 8-342 ( $\mathrm{HfO}_{2}$ (tetragonal)); JCPDS no. 00-053-0560 ( $\left.\mathrm{HfO}_{2}(\mathrm{fcc})\right)$.

[30] O. Ohtaka, H. Fukui, T. Kunisada and T. Fujisawa, J. Am. Ceram. Soc., $\underline{84}, 1369$ (2001).

[31] C. Dubourdieu, E. Rauwel, H. Roussel, F. Ducroquet, B. Holländer, M. Rossell, G. Van

Tendeloo, S. Lhostis and S. Rushworth, J. Vac. Sci. Technol. A, 27, 503 (2009).

[32] S. Chen, Z. Liu, L. Feng and X. Zhao, Appl. Phys. Lett., 103, 132902 (2013). 
[33] D. Fischer and A. Kersch, Appl. Phys. Lett., 92, 012908 (2008).

This manuscript was accepted by J. Appl. Phys. Click here to see the version of record.

1 [34.] O. Ohtaka, T. Yamanaka and S. Kume, J. Am. Ceram. Soc., 78, 233 (1995).

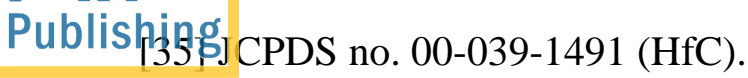

[36] JCPDS no. 01-071-4634 (Hf (hexagonal)).

[37] J. Jiang, R. I. Gomez-Abal, P. Rinke and M. Scheffler, Phys. Rev. B, 81, 085119 (2010).

[38] J. G. Bendoraitis and R. E. Salomon, J. Phys. Chem., $\underline{69}, 3666$ (1965).

[39] M. Balog and M. Schieber, Thin Solid Films, $\underline{41}, 247$ (1977).

[40] N. V. Nguyen, A. V. Davydov, D. Chandler-Horowitz and M. M. Frank, Appl. Phys. Lett., 87, 192903 (2005).

[41] A. Ortega, E. J. Rubio, K. Abhilash and C. V. Ramana, Opt. Mater., 35, 1728 (2013).

[42] J. -W. Park, D. -K. Lee, D. Lim, H. Lee and S. -H. Choi, J. Appl. Phys., 104, 033521 (2008).

[43] M. Di, E. Bersch, A, C. Diebold, S. Consighio, R. D. Clark, G. J. Leusink and T. Kaack, J. Vac. Sci. Technol. A, 29, 041001 (2011).

[44] Y. Xie, Z. Ma, Y. Su, Y. Liu, L.Liu, H. Zhao, J. Zhou, Z. Zhang, J. Li and E. Xie, J. Mater. Res., 26, 50 (2011).

[45] G. Lucovsky, C. C. Fulton, Y, Zhang, Y. Zou, J. Luning, L. F. Edge, J. L. Whitten, R. J. Nemanich, H. Ade, D. G. Schlom, V. V. Afanase'v, A. Stesmans, S. Zollner, D. Triyoso and B.

R. Rogers, IEEE/Trans. Device Mater. Rel., $\underline{5}, 65$ (2005).

[46] F. Espinosa-Magaña, A. Duarte- Moller, R. Martínez-Sánchez and M. Miki-Yoshida, J. Electron. Spectrosc., 125, 119 (2002).

[47] D. A. Neumayer and E. Cartier, J. Appl. Phys., 90, 1801 (2001).

[48] T. Hirata, Phys. Rev. B, $\underline{50}, 2874$ (1994).

[49] G. Rignanese and X. Gonze, Phys. Rev. B, 69, 184301 (2004). 
50] M. M. Frank, S. Sayan, S. Dörmann, T. J. Emge, L. S. Wielunski, E. Garfunkel and Y. J. This manuscript was accepted by J. Appl. Phys. Click here to see the version of record.

A Chabal, Mater. Sci. Eng. B-Adv., 109, 6 (2004).

Publishjpgr. J. Linstrom and W. G. Mallard, (eds.) in: NIST Chemistry WebBook, July 2001.

[52] T. Ali Cheema and G. Garnweitner, CrystEngComm, 16, 3366 (2014).

[53] E. P. Gusev, E. Cartier, D. A. Buchanan, M. Gribelyuk, M. Copel, H. Okorn-Schmidt and C. D'Emic, Microelectron. Eng., 59, 341 (2001).

[54] K. Kukli, J. Ihanus, M. Ritala and M. Leskela, Appl. Phys. Lett., 68, 3737 (1996).

[55] P. K. Karahaliou, N. Xanthopoulos, C. A. Krontiras and S. N. Georga, Phys. Scripta, $\underline{86}$, 065703 (2012).

[56] Z. J. Yan, R. Xu, Y. Y. Wang, S. Chen, Y. L. Fan and Z. M. Jiang, Appl. Phys. Lett., $\underline{85}$, 85 (2004).

[57] H. Wang, Y. Wang, J. Feng, C. Ye, B. Y. Wang, H. B. Wang, Q. Li, Y. Jiang, A. P. Huang and Z. S. Xiao, Appl. Phys. A, 93, 681 (2008).

[58] S. S. Hullavarad, D. E. Pugel, E. B. Nones, R. d. Vispute and T. Venkatesan, J. Electron. Mater., $\underline{36}, 648$ (2007).

[59] G. -M. Rignanese, X. Gonze and A. Pasquarello, Phys. Rev. B, 63, 104305 (2001).

[60] M. A. Pugachevskii and V. I. Panfilov, Tech. Phys. Lett., 41, 291 (2015).

[61] M. A. Pugacheyskii and V.,. Panfilov, Inorg. Mater. 50, 582 (2014).

[62] D. A. G. Bruggeman, Ann. Phys. (Leipzig), 24, 636 (1935).

[63] M. C. Cheynet, S. Pokrant, F. D. Tichelaar and J. -L. Rouvière, J. Appl. Phys., 101, 054101 (2007).

[64] See supplemental material at [URL] for the parallel plates capacitor model, bottles with the nanoparticles colloidal solutions, rescaled XRD data for the nanoparticles synthesized in DI water using the different energies, gold top electrodes and capacitance data for additional samples including a data summarizing Table. 


\section{FIGU RE CAPTIONS}

This manuscript was accepted by J. Appl. Phys. Click here to see the version of record.

A ElG. 1. TEM images and corresponding size distribution histograms of the nanoparticles

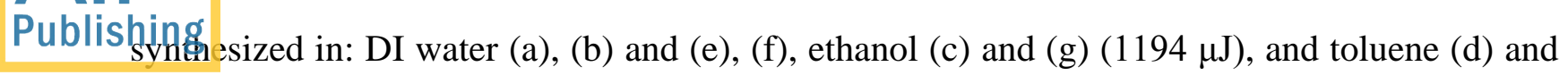
(h) $(380 \mu \mathrm{J})$, respectively.

FIG. 2. XRD patterns of the nanoparticles.

FIG. 3. UV-vis absorption spectra measured from the nanoparticles colloidal solutions (as measured).

FIG. 4. Plots of $(\alpha \omega)^{2}$ versus energy calculated from the spectra of Fig. 3, from which the energy gaps were determined.

FIG. 5. FTIR transmission spectrum from the hafnia nanoparticles (1194 $\mu \mathrm{J}$ in DI water).

FIG. 6. Schematic of the structure fabricated for the measurement of the dielectric properties of hafnia nanoparticles thin film deposited on the substrate by drop-casting from the colloidal solution (self-assembled layer).

FIG. 7. Real (a) and imaginary (b) part of the admittance versus frequency, and plots of the slope of the real part (c) and of the capacitance (d) versus the device area for sample 1. Data for other samples are given in the Supplementary Material (Table 1 and Fig. S5 and S6 [64]). 

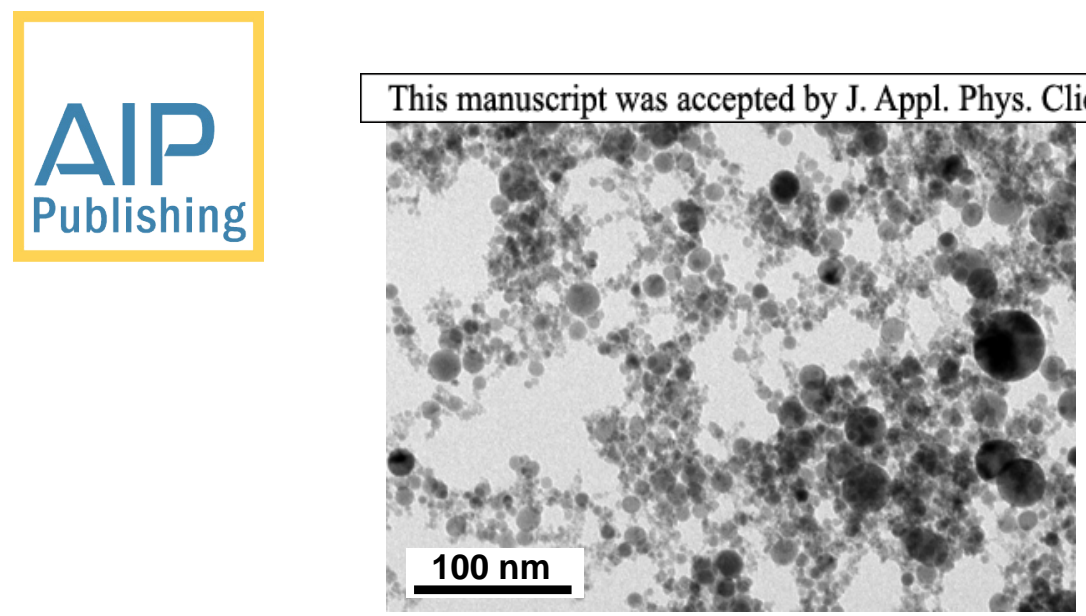

(a)
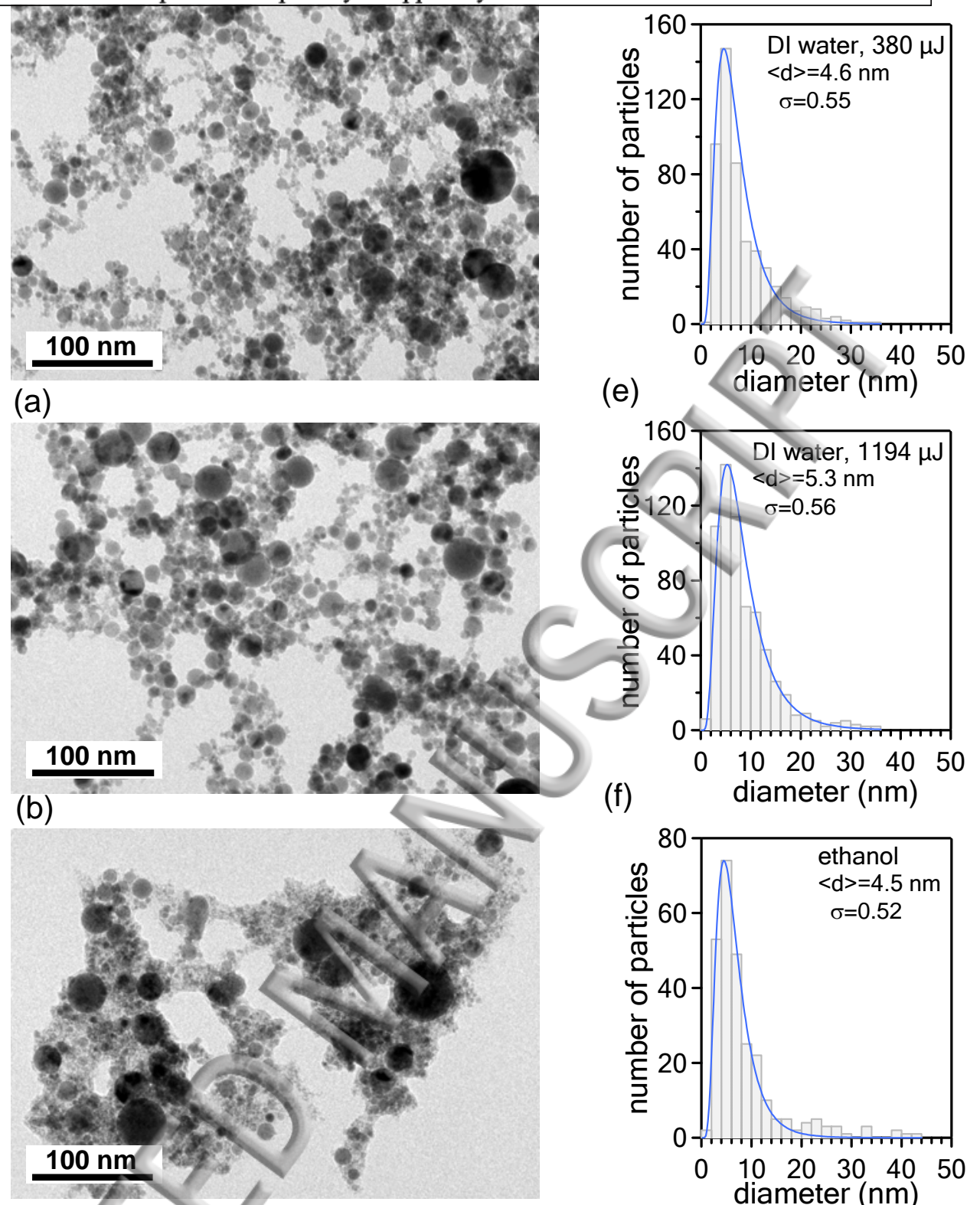

(c)

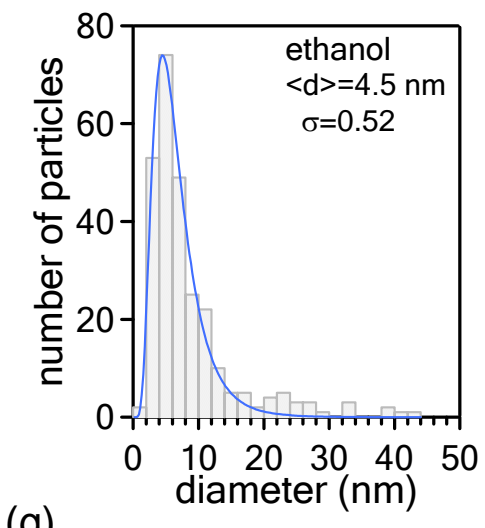

(g)

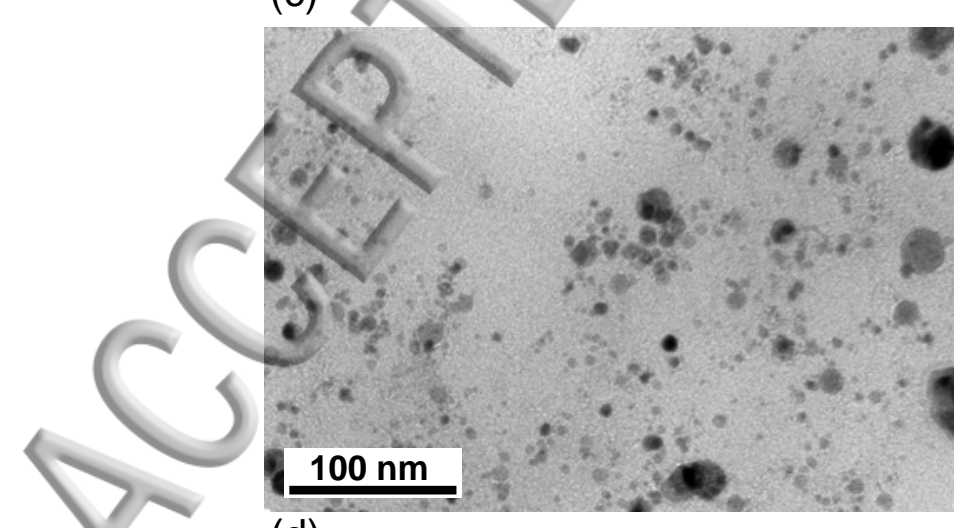

(d)

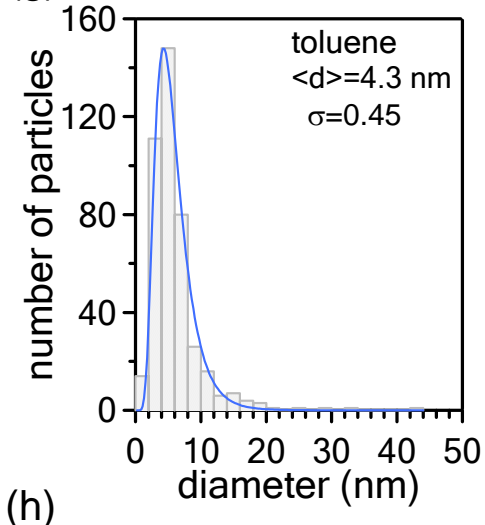

Fig. 1 

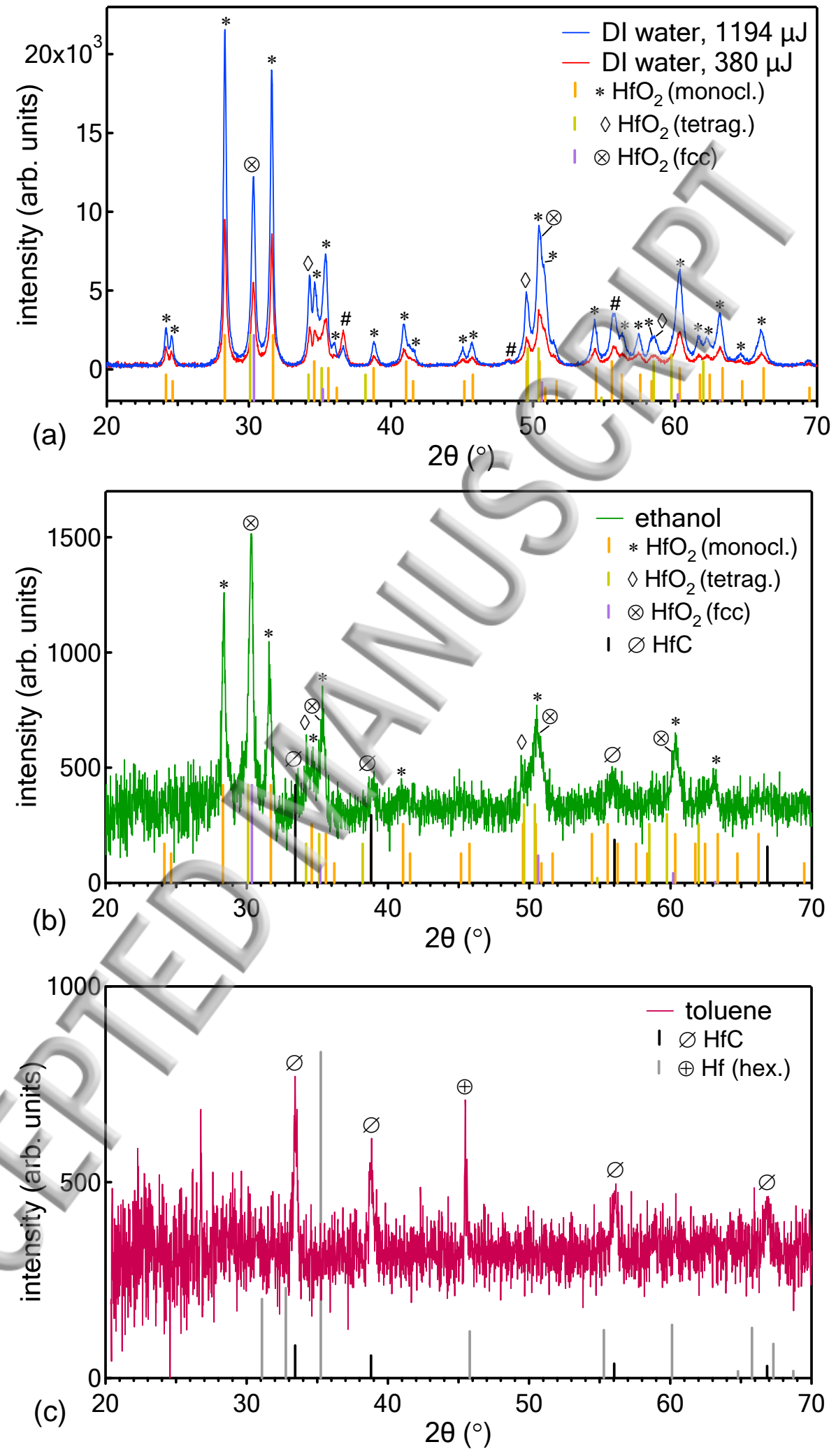

Fig. 2 

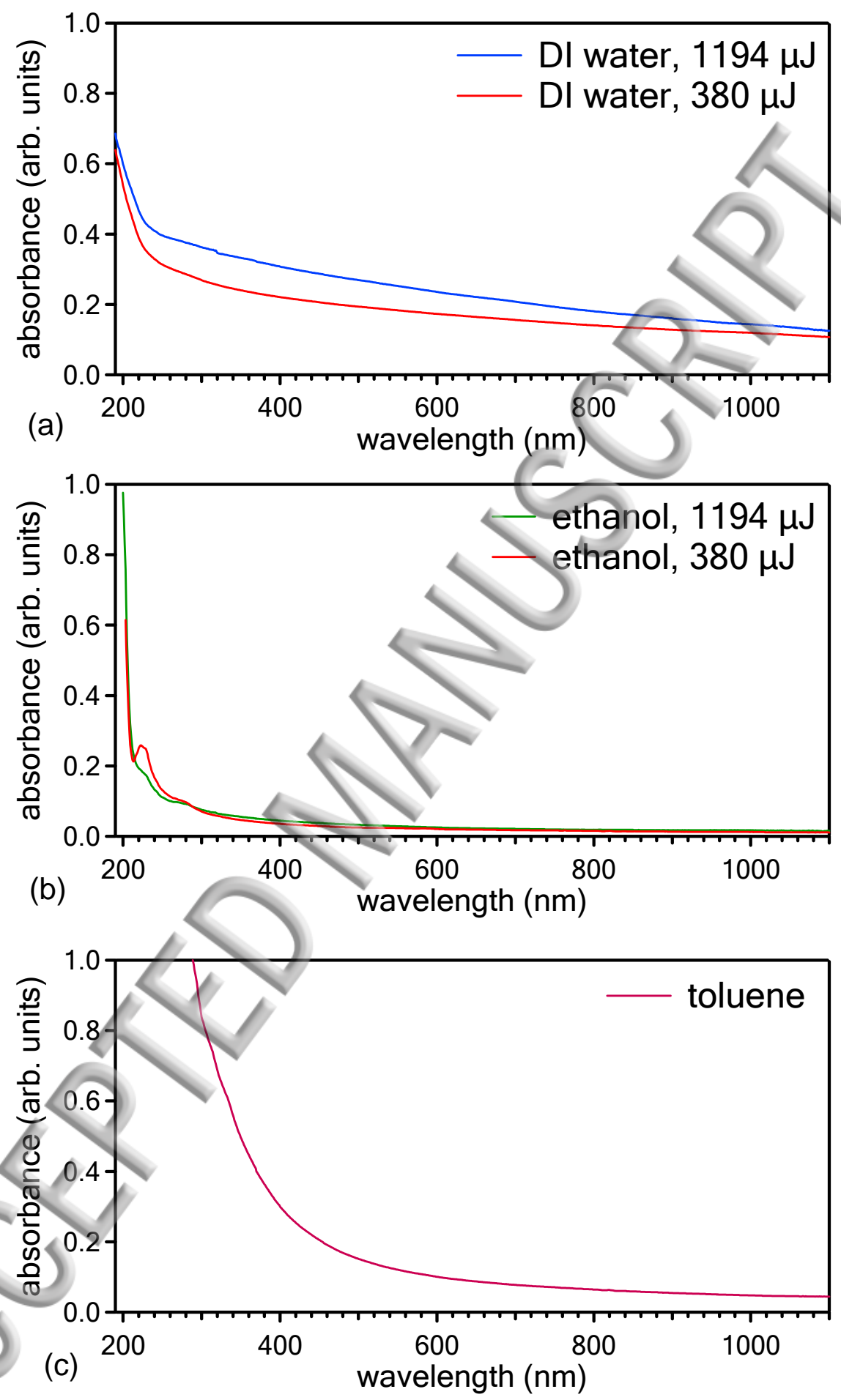

Fig. 3 

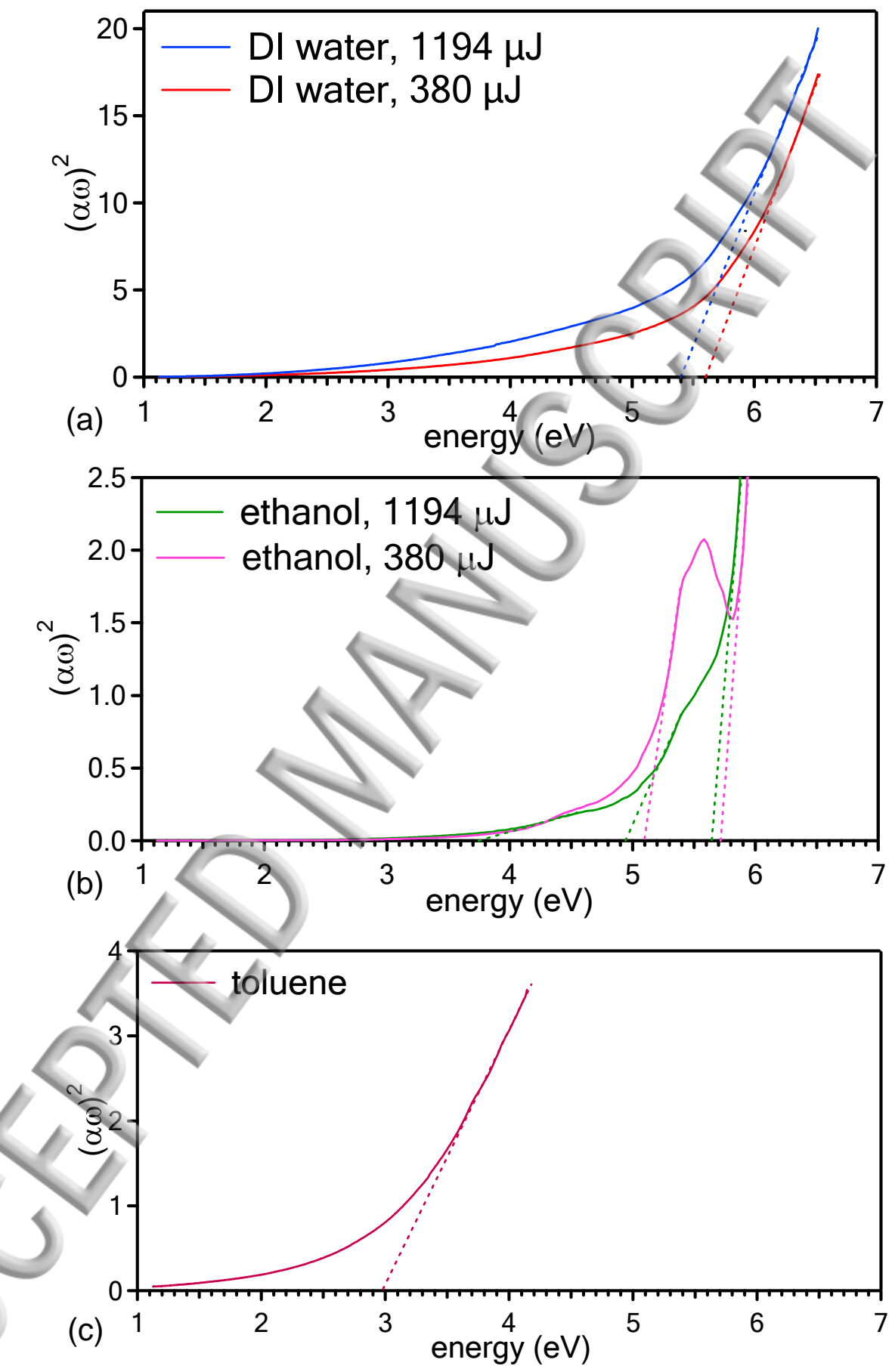

Fig. 4 


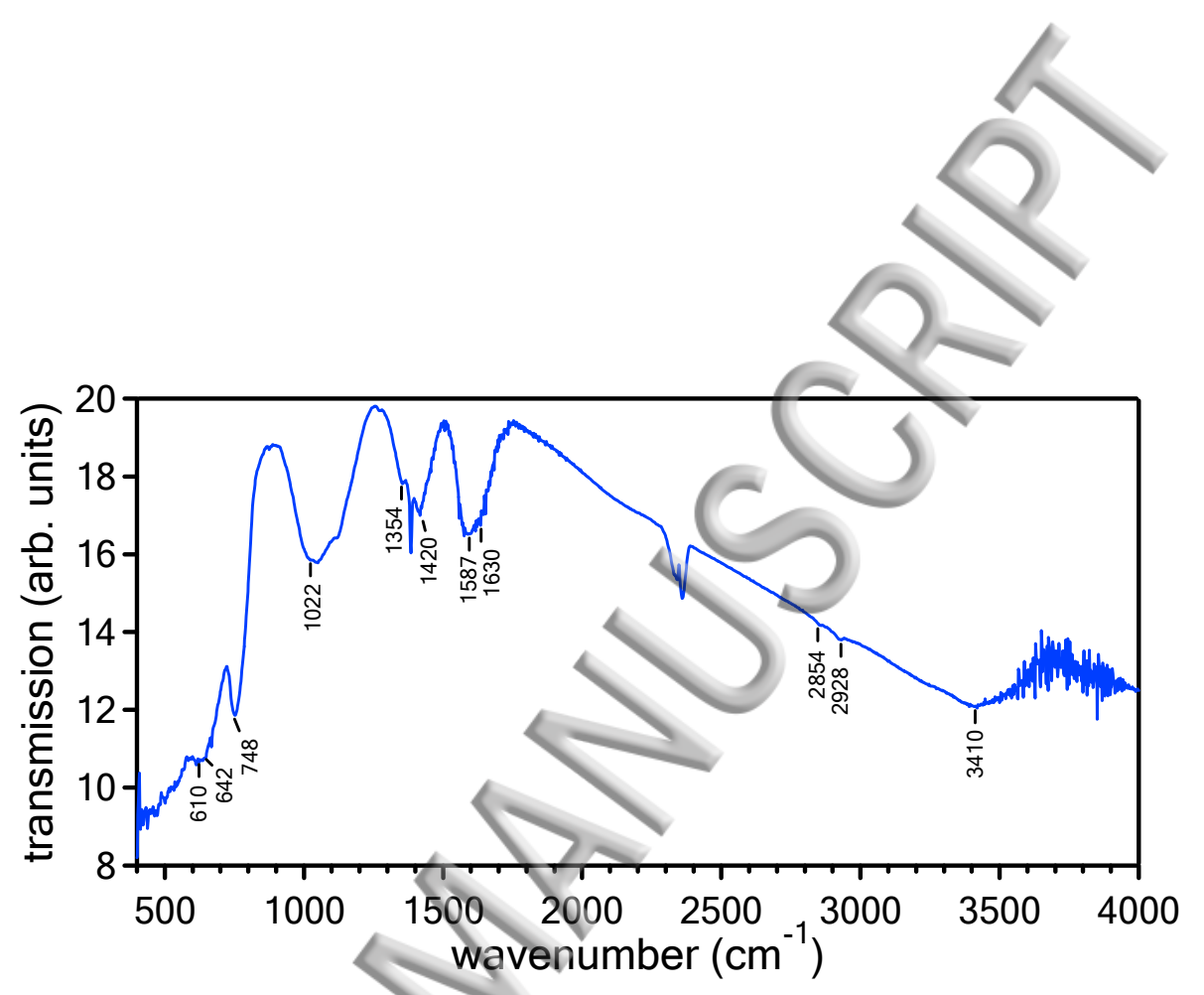

Fig. 5 


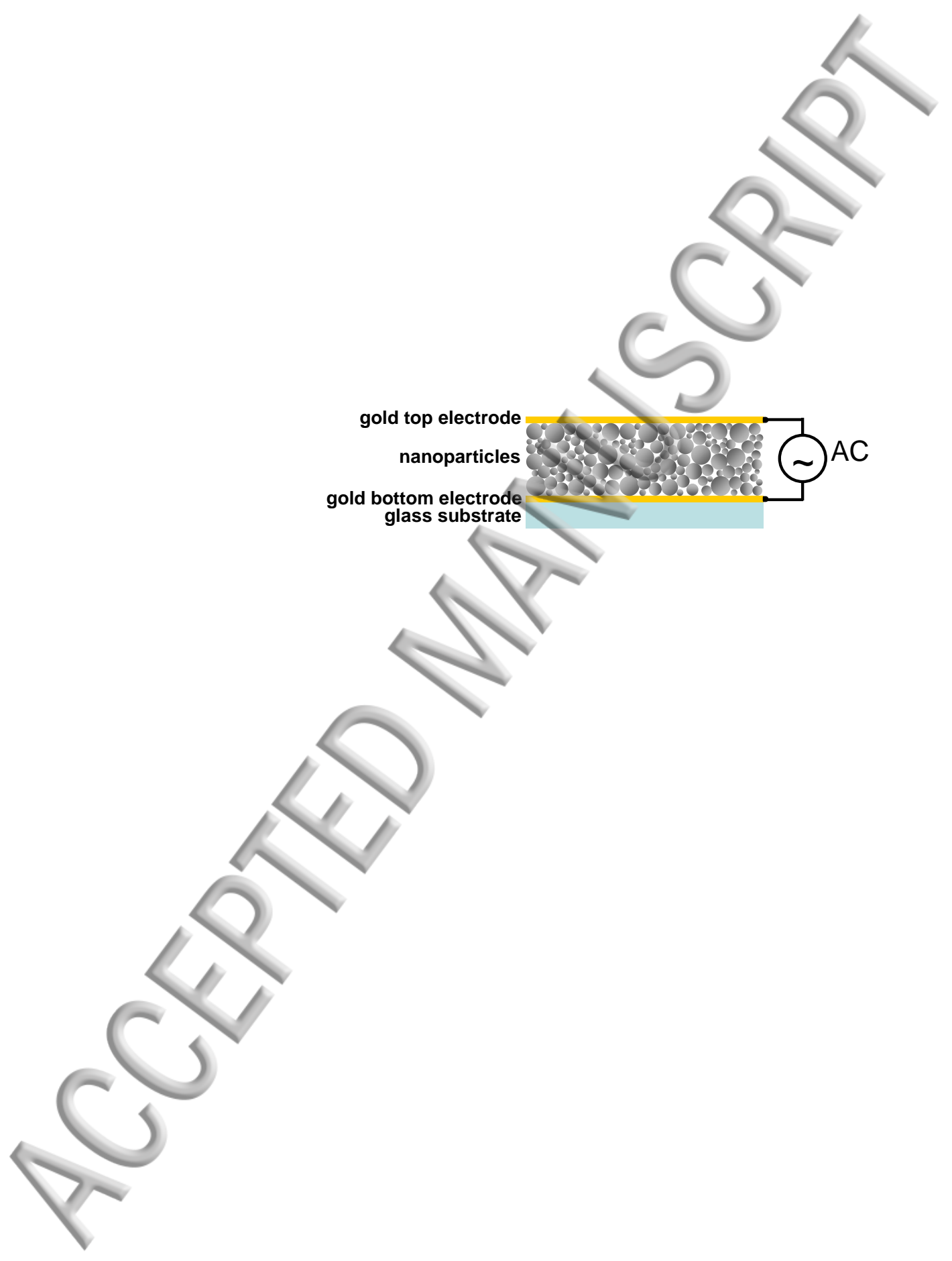

Fig. 6 

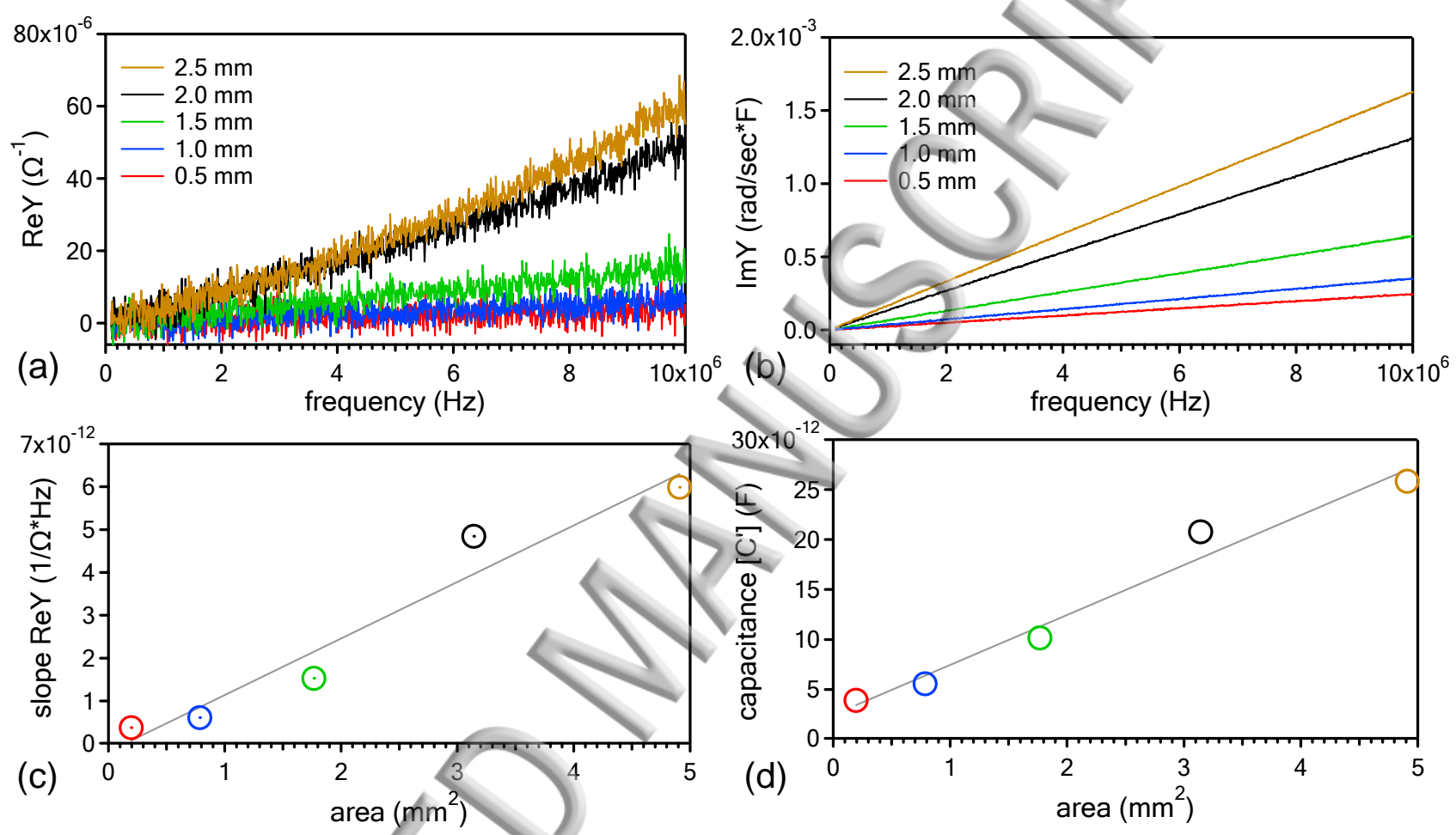

Fig. 7 